C. Editorial Note: Footnote 18, p. 397, (with one correction and the additional location of 18 more library copies), is here reprinted; for information concerning 6 of these copies we are indebted to the Librarian of the Houghton Library, Harvard University: Prof. W. A. JACKSON.

[19966a]. A Canon of Triangles, [1614], entered in the Stationers' Company Register 17

Jan. 1614. No place of publication, no printer's name, no date. No entry in $S T C$; here identified for the first time. Signatures A-L4, $\mathrm{M}^{2}$.

Library Copies: British Museum, Brown Univ., Mr. Harrison D. Horblit of New York, Huntington Lib., Lincoln Cathedral, Trinity College, Cambridge.

19966. [Anr. ed.] 1630. 4to. T. Purfoot for J. Tapp, 1630.

Library Copies: Boston Public Lib., British Museum (omitted in STC), Univ. Cambridge, Christ Church College Lib., Crawford Lib., Huntington Lib., Univ. Liverpool, Univ. Michigan, U. S. Naval Observatory (2 copies), Yale Univ.

19967. Trigonometry. Tr.Ra: Handson, 1614.

Library Copies: Bodleian, British Museum, Mr. Harrison D. Horblit, Huntington Lib., Lincoln Cathedral, Dr. Daniel Williams Lib., London.

19968. [Anr. ed.], 1630.

Library Copies: Boies-Penrose Lib., Boston Public Lib., British Museum (omitted in $S T C)$, Christ Church College Lib., Huntington Lib., Univ. Liverpool, Pembroke College L.ib., U. S. Naval Observatory, Univ. College, London, Yale Univ.

19968a. [Anr. ed.], 1631. Entered in the Stationers' Company Register 1 Aug. 1631.

Library Copies: Univ. Cambridge, Cashell Lib. (Ireland), Crawford Lib., Univ. Illinois, Univ. Michigan, U. S. Naval Observatory. Not in the Huntington Lib. $(S T C H)$, as stated in $S T C$.

\title{
CORRIGENDA
}

V. 1 , p. 479 , delete Weber, H. M. and all page references which follow. Then add

Weber, H. F. 722, 108, 206, 219, 220, 244, 245, 278, 294, 335, 446

Weber, H. M. $199^{2}, 293,303,307$

V. 3, p. 40, 1. 6, delete Von; p. 314, 1. 12, delete Pidduck,; p. 361, for 593[K], read 593[I, U]; p. 385, for Lancros, read Lanczos; p. 391, 1. -4, -5, for It is a $7 \mathrm{D}$ table for sin, cos; 7-8D table for tan, cot; 8-9D table for sec, csc., read The tables, mainly 7D, are for the six trigonometric functions, but they are 7-12D for $\sin , \cos ; 5-7 \mathrm{D}$ for tan, cot; 5-12D for sec, csc; p. $424,1.1$, for $n>0$, read $n \geq 0$.

\section{Symposium Announcement}

A second Symposium on large-scale digital calculating machinery is to be held at the Computation Laboratory of Harvard University in eight sessions, September 13 through 16, 1949. The program at present is being prepared and will be announced about July first. It is planned that especial consideration shall be given to the application of computing machinery to the solution of problems in the physical and social sciences. Mark III Calculator will be operating under test conditions before shipment to the Naval Proving Ground, Dahlgren, Virginia.

H. H. AIKEN 